belt use patterns in Delhi, India, and the implications for effectiveness of traffic safety interventions.

Methods In September 2014 we conducted roadside traffic surveys at 17 locations and observed 3,251 MTWs and 3,200 cars. All surveys were done between 0700 and 1900 hours. The following data were recorded: Number and sex of passengers by their location in the vehicle, seatbelt use by car occupants and helmet use by MTW occupants. The data are analysed for estimating the effectiveness helmet and seatbelt laws and the outcome in terms of lives saved.

Results MTW use patterns: Total MTW: 3251; Passengers per MTW: 1.3; Children per 100 MTW: 3; Overall helmet wearing rate: $88 \%$; Driver helmet wearing rate: 96\%; Pillion helmet wearing rate: $70 \%$.

Car use patterns: Total Cars: 3,200; Passengers per car: 2.0; Overall belt use 60.3\%; Driver belt use: 91.5\% ; Front seat passenger belt use: 76\%, Rear seat passenger belt use: $6 \%$.

Fatality rate estimates per billion vehicle- $\mathrm{km}$ in Indian cities: Delhi: Car-3.8, MTW - 16.5; Average for 5 other Indian metropolitan cities where helmet laws are not enforced and seat belt law enforcement is weak: Car - 12.5, MTW - 37.7.

Conclusions Helmet wearing rates for MTW riders exceeds $88 \%$ in Delhi where the law is enforced as compared to less than $20 \%$ in other Indian cities where the law is not enforced. Between the years 1999 and 2014 helmet use by women passengers was insignificant, but increased to more than $70 \%$ immediately after the mandatory law was reintroduced. Belt use by front seat car passengers in Delhi is $76 \%$. This shows that publicity campaigns do not result in high belt and helmet use, but enforcement of mandatory laws has a very strong effect on compliance.

Fatality rates per billion vehicle $\mathrm{km}$ in Delhi for cars are 30\% of those in other cities and for MTW 44\%. The lower rates in Delhi are probably partly due to enforcement of helmet and seatbelt use laws.

\section{REGULATIONS AND ENFORCEMENT IN OFF-HIGHWAY VEHICLE PARKS IS ASSOCIATED WITH SAFER RIDING BEHAVIOURS}

Charles Jennissen, Jessica Waters, Gerene Denning, Emily Robinson, Eilis Baranow, Brandon Johnson, Nathaniel Johnson, Kristel Wetjen, Pam Hoogerwerf, Karisa Harland. University of lowa, USA

\subsection{6/injuryprev-2016-042156.663}

Background Previous studies showed that Iowa all-terrain vehicle (ATV) crash victims from off-highway vehicle (OHV) parks practiced safer riding behaviours than off-road crash victims outside the parks. The objective of this study was to determine the effect of regulations and enforcement on the prevalence of safety behaviours among Iowa OHV park users.

Methods From May to September of 2014, motion-activated cameras captured photos of users at the entrances of Iowa's eight OHV parks. Riders were coded by vehicle type, estimated age, sex, and safety behaviours. Descriptive and multivariable logistic regression analyses were performed.

Results A total of 6,718 vehicles and 9,083 riders were analysed. Among OHV park users, 44\% were on ATVs, 51\% on dirt bikes and $5 \%$ on side-by-sides (SxSs). Helmet use was $94 \%$ overall. Just $6 \%$ of single-rider ATVs and $0.8 \%$ of dirt bikes had passengers. While only $11 \%$ of park users on ATVs were $<16$ years old, 59\% of the child operators were driving adult sized ATVs. Of those riding SxSs, 64\% were not using their restraints. As compared to young adult (16-39 years) ATV riders, children were $\sim 6$ times more likely to wear a helmet and adults $40-60$ years old were half as likely. When officers were patrolling the parks, there was a 3.6-fold higher likelihood of helmet use and a $40 \%$ lower likelihood of passengers on dirt bikes and ATVs.

Conclusions Regulated safety behaviours (helmet use and riding without passengers) were highly common among OHV park users. However, unregulated behaviours $(\mathrm{S} x \mathrm{~S}$ restraint use and children driving youth-sized ATVs only) had lower compliance. Moreover, regulated safety behaviours were significantly increased when the parks were patrolled. This study shows that a combination of regulation and enforcement is effective in ensuring safety behaviour compliance in OHV parks. Similar efforts outside parks could have a substantial effect on decreasing offroad vehicle-related deaths and injuries.

\section{A NEEDS ASSESSMENT OF OPPORTUNITIES FOR SAFE BICYCLING IN AN URBAN AREA}

${ }^{1}$ Keshia M Pollack, ${ }^{2}$ Chavi Rhodes. 'Johns Hopkins Centrefor Injury Research and Policy, Baltimore, MD, USA; Independent Research Consultant, USA

\subsection{6/injuryprev-2016-042156.664}

Background Bicycling has been proposed as a potential intervention to reduce sedentary lifestyles, decrease air pollution, and promote active transportation. This study sought to assess the knowledge, attitudes, and behaviours towards bicycling in an urban area, explore the dominant safety concerns for bicyclists, and understand equity issues.

Methods A sequential mixed-methods design was used for this study. Data were first collected from an online survey administered from mid-February 2014 through April 1, 2014. Quantitative data guided the focus of key informant interviews with a purposive sample of policymakers and advocates, and a focus group of neighbourhood residents. A literature and document review supplemented the quantitative and qualitative data. Data analysis involved identifying key themes across all data. Findings were disseminated to City leaders.

Results The online survey was completed by 1,437 City residents (62\% were regular riders). Nearly three-quarters of the respondents did not feel safe riding in the City. The leading safety concerns were motorists, lack of room to ride, uneven road surfaces, and the potential for crime. Only $37 \%$ of respondents said that the bicycling community was representative of the City in terms of gender, race, and age. Qualitative data identified youth and Latin Americans as populations who use bicycles as their primary mode of transportation. Key informants emphasised the safety risks, and acknowledged that the City suffers from inadequate infrastructure for cyclists. Respondents also highlighted significant inequities in neighbourhoods where investments in infrastructure have been made.

Conclusions People who ride regularly and those who are nonriders, but are interested in riding more, reported feeling unsafe. Efforts to improve safe cycling should enhance enforcement of traffic laws targeting motorists and bicyclists and improve bicycling infrastructure throughout the City. 